\title{
Should we worry about filter bubbles?
}

\section{Frederik J. Zuiderveen Borgesius}

Institute for Information Law (IViR), University of Amsterdam, Amsterdam, The Netherlands

\section{Damian Trilling}

Department of Communication Science, University of Amsterdam, Amsterdam, Netherlands

\section{Judith Möller}

Department of Communication Science, University of Amsterdam, Amsterdam, Netherlands

\section{Balázs Bodó}

Institute for Information Law (IViR), University of Amsterdam, Amsterdam, Netherlands, bodo@uva.nl

\section{Claes H. de Vreese}

Department of Communication Science, University of Amsterdam, Amsterdam, Netherlands

\author{
Natali Helberger \\ Institute for Information Law (IViR), University of Amsterdam, Amsterdam, Netherlands
}

Published on 31 Mar 2016 | DOI: 10.14763/2016.1.401

\begin{abstract}
Some fear that personalised communication can lead to information cocoons or filter bubbles. For instance, a personalised news website could give more prominence to conservative or liberal media items, based on the (assumed) political interests of the user. As a result, users may encounter only a limited range of political ideas. We synthesise empirical research on the extent and effects of self-selected personalisation, where people actively choose which content they receive, and pre-selected personalisation, where algorithms personalise content for users without any deliberate user choice. We conclude that at present there is little empirical evidence that warrants any worries about filter bubbles.
\end{abstract}

Keywords: Filter bubble, Personalisation, Selective exposure

\section{Article information}

Received: 06 Oct 2015 Reviewed: 15 Feb 2016 Published: 31 Mar 2016

Licence: Creative Commons Attribution 3.0 Germany

Competing interests: The author has declared that no competing interests exist that have influenced the text.

URL: http://policyreview.info/articles/analysis/should-we-worry-about-filter-bubbles

Citation: Zuiderveen Borgesius, F. J. \& Trilling, D. \& Möller, J. \& Bodó, B. \& de Vreese, C. H. \& Helberger, N. (2016). Should we worry about filter bubbles?. Internet Policy Review, 5(1).

https://doi.org/10.14763/2016.1.401 


\section{INTRODUCTION}

Media content is becoming increasingly personalised. Before the advent of digital media, news outlets generally featured exactly the same content for all users. Now, in theory, the same news website can show each visitor personalised content. Such personalisation has led to worries about filter bubbles and selective exposure: personalised content and services could limit the diversity of media content people are exposed to and thus have an adverse effect on the democratic discourse, open-mindedness and a healthy public sphere (e.g., Pariser, 2011; Sunstein, 2002). For instance, the High Level Expert Group on Media Diversity and Pluralism, an independent group advising the European Commission, warned for the impact of personalised communication on our democratic society:

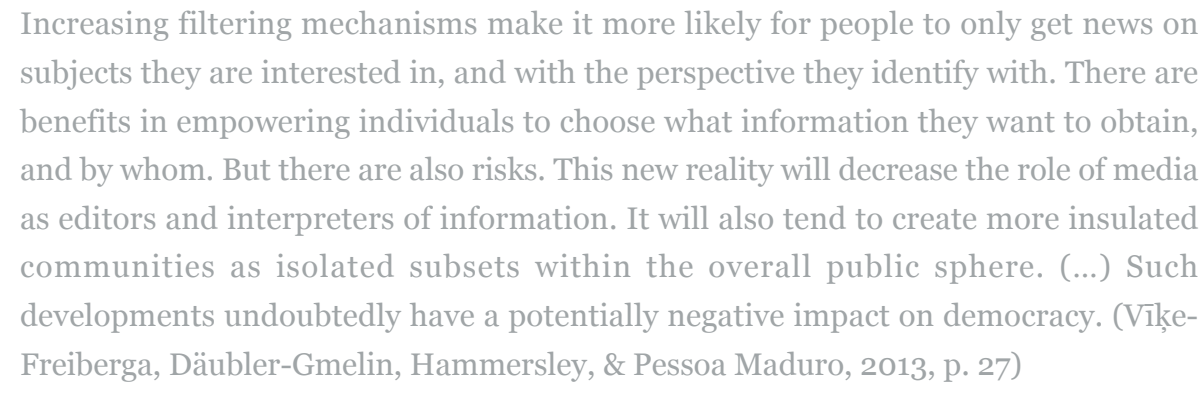

A dire warning, but is it true? How personalised are online news media today? What are the effects of personalised media on media exposure and the information choices people make? Even harder questions concern the long-term effects of personalisation. Does personalised content really influence consumers, newsreaders, citizens, and voters in a negative manner? Are concerns about filter bubbles supported by empirical evidence?

To address these questions, we provide an overview of concerns that have dominated the public information policy discourse, and review the main insights from empirical research. For this paper, personalisation is described as the phenomenon that media content is not the same for every user, but tailored to different groups or individuals.

In Section 2, we introduce the notion of personalisation, and distinguish self-selected personalisation from pre-selected personalisation. In Section 3, a brief overview is given of the main concerns about filter bubbles in current public policy discourse, based on a review of policy documents. Then, we review empirical evidence of the prevalence (Section 4) and effects (Section 5) of personalised communication.

\section{SELF-SELECTED AND PRE-SELECTED PERSONALISED COMMUNICATION}

In his book Being Digital, Negroponte (1995) discussed the idea of the 'daily me'. He suggested that people would soon be able to choose their own personalised media experiences: 
newspaper and catch every TV and radio broadcast on the planet, and then construct a personalized summary. This kind of newspaper is printed in an edition of one."

(Negroponte, 1995, p. 153)

Others worry that people can lock themselves in information cocoons or echo chambers. For instance, somebody might read only left-leaning blogs and websites, listen only to left-leaning radio, and watch only left-leaning television. Pariser coined the term 'filter bubble', "a unique universe of information for each of us" (Pariser, 2011, p. 9). For example, a personalised news website could give more prominence to conservative media items, based on the inferred political interests of the user. When they form their political ideas, users of such personalised services may encounter fewer opinions or political arguments.

We distinguish between two main types of personalisation: self-selected personalisation and pre-selected personalisation. Others have used different terms to describe similar phenomena: For instance, self-selected personalisation could also be called 'explicit personalisation', and pre-selected personalisation could be called 'implicit personalisation' (Thurman \& Schifferes 2012; see also Treiblmaier, Madlberger, Knotzer, \& Pollach, 2004).

Self-selected personalisation concerns situations in which people choose to encounter likeminded opinions exclusively. For example, a person who opposes immigration might want to avoid information that specifies how much a country has gained due to immigration, while paying a lot of attention to news stories about problems related to immigration. People tend to avoid information that challenges their point of view, for example by avoiding news outlets that often feature editorials that favour an opposing political camp. In communication science, this phenomenon is conceptualised as selective exposure (e.g. Stroud, 2011).

Pre-selected personalisation concerns personalisation driven by websites, advertisers, or other actors, often without the user's deliberate choice, input, knowledge or consent. Concerns about pre-selected personalisation are often summarised with the term 'filter bubble' (Pariser, 2011).

Pre-selected personalisation may be chosen by the user, or not. For instance, some people may realise that Facebook personalises the content in its newsfeed. If these people explicitly use Facebook to see the curated, pre-selected collection of news about 'friends', the newsfeed is an example of chosen pre-selected personalisation. Other people, however, may not realise that the newsfeed on Facebook is personalised; those people do not explicitly choose pre-selected personalisation.

\section{CONCERNS AROUND PERSONALISED COMMUNICATION}

Below, we summarise the main concerns regarding personalisation that have been brought forward in policy and scholarly circles. We discuss the effects of personalisation on democracy, the role of new gatekeepers and influencers of public opinion, autonomy-related concerns, the lack of transparency around personalisation, and the possibilities for social sorting. Examining the privacy implications of the massive collection of user data that is often involved in personalisation lies beyond the scope of this paper (for privacy implications of personalised services, see Zuiderveen Borgesius, 2015). 


\section{EFFECTS ON DEMOCRACY}

Many worry about the effects that personalised communication could have on democracy. When the High Level Expert Group on Media Diversity and Pluralism commented on personalisation strategies in the media, one of its main concerns was that people would encounter fewer opinions, which could have a negative effect on the public sphere and the democratic opinion forming process (Vike-Freiberga et al., 2013). In a similar vein, the Council of Europe (2012, Appendix, Section I, paragraph 2) warned that the ordering and ranking of information in the context of search engines can affect information access and the diversity of information people are exposed to.

The concerns of the Expert Group echo arguments made in the scholarly debate, including those by Sunstein (to whom the group refers) (Viķe-Freiberga et al., 2013). Sunstein discusses risks of too much personalisation. He mainly addresses self-selected personalisation: people locking themselves in 'information cocoons', which he describes as "communication universes in which we hear only what we choose and only what comforts us and pleases us" (Sunstein 2006, p. 9). To give a current example: somebody might self-select personalisation by following people on Twitter who hold like-minded opinions.

Sunstein discusses two risks of personalisation. First, in a democratic society people need to come across opinions that differ from their own opinions, to develop themselves fully. Otherwise, people might enter a spiral of attitudinal reinforcement and drift towards more extreme viewpoints (Sunstein 2002, p. 9). This is a point also shared by the Expert Group: "The concern is people forgetting that alternatives do exist and hence becoming encapsulated in rigid positions that may hinder consensus-building in society" (Viḳe-Freiberga et al., 2013, pp. 2728). Sunstein warns that "unplanned, unanticipated encounters are central to democracy itself" (2002, p. 9).

Second, if people locked themselves in their own information cocoons, they might have fewer common experiences. Sunstein says a diverse democratic society needs shared experiences as 'social glue' (2002, p. 9). The Habermasian understanding of the public sphere, in which societally relevant ideas are formulated, negotiated and distributed, and in the process the ruling authorities' actions are kept under control and guided (Habermas, 1989), still serves as an important point of reference, despite the extensive critique this idea rightly received.

\section{NEW GATEKEEPERS AND INFLUENCERS OF PUBLIC OPINION}

In the public policy discourse, much attention is given to search engines, app stores, and social network sites as new gatekeepers and influencers of public opinion (see e.g., European Commission, 2013, p. 13; Vikge-Freiberga et al., 2013). There is a long tradition in media law and policy of regulating gatekeeper control, because such control can threaten the realisation of important public policy goals, such as media diversity, public debate and competition on the marketplace of ideas.

However, the new information intermediaries, such as providers of search engines, social network sites, and app stores, differ in many respects from the more traditional gatekeeper categories, like the old press barons and controllers of content and infrastructure. One of the most important differences is the set of mechanisms used to exercise gatekeeping control which, in the case of the new intermediaries, are often related to interaction with users, the amount of knowledge and control they have over the user base, and exposure to diverse information (Helberger, Kleinen-von Königslöw, \& Van der Noll, 2015). 
An experiment in which Facebook persuaded its users to vote in the US election demonstrates the power of new opinion influencers well. The "results suggest that the Facebook social message increased turnout directly by about 60,000 voters and indirectly through social contagion by another 280,000 voters, for a total of 340,000 additional votes. That represents about $0.14 \%$ of the voting age population of about 236 million in 2010" (Bond, Fariss, Jones, Kramer, Marlow, Settle, \& Fowler, 2012, p. 1). Because of the potential power of gatekeepers, various scholars call for meaningful transparency regarding their algorithms and their profiling practices (Hildebrandt \& Gutwirth, 2008; Pasquale, 2015; Bozdag, 2015).

\section{AUTONOMY-RELATED CONCERNS}

Personalised communication may also restrict people's autonomy, according to some authors (e.g. Zarsky 2002, p. 42). In brief, people's opinions might be steered by personalised media, while they are not aware of being influenced.

However, personalisation, at least self-selected personalisation, could also enhance people's autonomy, because people can express which content they wish to receive. In contrast, in the traditional mass media situation, the editor determines which content is presented in which form. In other words, personalisation strategies can also have an empowering effect on users. In fact, pre-selected personalisation can also be used to help users make more diverse choices (Helberger, 2011).

\section{LACK OF TRANSPARENCY}

Another prominent item on the media policy agenda is the lack of transparency regarding preselected personalisation. The lack of transparency could affect the way people respond to personalised messages (Vikge-Freiberga et al., 2013), and could make it harder for regulators to monitor the media sector. If people do not realise they see pre-selected content, they might think they see the same content as everybody else.

The Council of Europe seems to suggest that transparency about the search algorithm can help to promote media diversity and information access, and help to mitigate the filter bubble risk (Council of Europe, 2012, paragraph 7 and Appendix, Section 1, paragraph 4). Transparency in itself may not promote diversity of supply and exposure, but transparency is a necessary, albeit insufficient condition to detect problems with diversity. It is also unclear whether information about the way search engines work can cause people to choose more diverse content or can help people to avoid being trapped in a filter bubble. However, transparency about personalisation is at least essential to inform the policy discussions.

\section{SOCIAL SORTING}

Topics that received little attention in the public policy discourse on personalised communication are social sorting and discriminatory practices. Scholars have paid more attention to these topics. Social sorting involves, in Lyon's words, "obtain[ing] personal and group data in order to classify people and populations according to varying criteria, to determine who should be targeted for special treatment, suspicion, eligibility, inclusion, access, and so on" (Lyon, 2003, p. 20). In particular, profiling and classification in one domain (for example in advertising) may outgrow its original context and define other domains of our life (Turow, 2011). Social sorting, thus, "may further erode the tolerance and mutual dependence between diverse groups that enable a society to work" (Turow, 2011, p. 196).

\section{CONCLUSION}

In public policy and academic discourse, personalised communication is regarded with much 
concern. Much of the existing public policy discourse makes little reference to empirical evidence, leaving unclear to what extent concerns are justified, exaggerated, or underestimated.

Empirical research into the extent of personalised communication, and its effects on access to diverse information, can serve as a reality check. Empirical research can help to adjust the priorities in public policy, and to identify areas in which we simply do not know enough to make any conclusive policy statements. Below, we focus on empirical evidence of the spread of personalised news services and its likely effects on political polarisation and political information.

\section{HOW COMMON IS PERSONALISATION?}

\section{PREVALENCE OF SELF-SELECTED PERSONALISATION}

Selectively using information that matches pre-existing beliefs is human. People tend to avoid media content that conflicts with their beliefs (Festinger, 1957). The first data on this were collected during a US election campaign in 1940: Democrats were more likely to be exposed to the Democratic Campaign, and Republicans to the Republican campaign (Lazarsfeld, Berelson, \& Gaudet, 1944). Many European countries have known a strong party press until the first half of the 2oth century, with people being exposed to mainly like-minded information (Hallin \& Mancini, 2004). A prime example is the period of pillarisation (verzuiling) in the Netherlands, where Catholics were commonly assumed to read a Catholic newspaper, to join a Catholic sports club, and to listen to Catholic radio. Left-voting labour workers had their own pillar, as did protestants (Lijphart, 1968; Wijfjes, 2004). Although the premise that the cleavages were that rigid has been challenged somewhat (Bax, 1988; Blom \& Talsma, 2000), being exposed to like-minded content was pretty likely.

Nevertheless, in a literature review from as early as 1967, Sears and Freedman (1967) contest the idea that selective exposure occurs because of cognitive dissonance. In the decades that followed, interest in the topic was lost, in part because media choice was limited to few TV channels and newspapers, rendering the mechanism somewhat irrelevant. Once the choice grew with the advent of cable TV and the internet, the topic gained renewed scholarly interest.

Whereas it is trivial to show that the audience of partisan media outlets in general is partisan as well, this does not have to be problematic from a normative point of view. It is insufficient to look at usage of isolated media outlets, because those who use a lot of partisan information also use an above-average amount of mainstream news (e.g., Bimber \& Davis, 2003; Trilling \& Schoenbach, 2015; Zaller, 1992). Furthermore, at least in Europe, most people by far still get their news via traditional sources, most notably public-service television (Blekesaune, Elvestad, \& Aalberg, 2012; Trilling \& Schoenbach 2013a, 2013b, 2015). The fact that fewer people watch mainstream TV news and read newspapers does not mean that people massively turn to alternative specialist outlets; most online outlets with a substantial reach are spin-offs of traditional media. Thus, those who use extremely partisan outlets are mostly exposed to moderate ideas as well. If there are echo chambers, the walls are pretty porous. Therefore, Garret distinguishes between selective exposure and selective avoidance: while there is some evidence that people select information they agree with, it is much less certain whether people actually avoid possibly conflicting information (Garret, 2009a, 2009b; Garret, Carnahan, \& Lynch, 2011).

In summary, people self-select information they agree with, but the importance of this might not 
be as dramatic as often suggested, because even if people self-select consonant content, they may well be confronted with conflicting content as well.

\section{PREVALENCE OF PRE-SELECTED PERSONALISATION}

In contrast to self-selected personalisation, pre-selected personalisation is not a result of a user's direct choice - but of a choice that is determined by algorithms. This is commonly known from recommendations on online shopping sites or on YouTube (O'Callaghan, Greene, Conway, Carthy, \& Cunningham, 2013) and in the context of online search results (Van Hoboken, 2012; Dillahunt, Brooks, \& Gulati, 2015). It is debatable how common and far-reaching pre-selected personalisation is. For example, there is some evidence that $11 \%$ of Google searches differ due to personalisation (Hannak, Sapiezynski, Molavi Kakhki, Krishnamurthy, Lazer, Mislove, \& Wilson, 2013). Whether this $11 \%$ is a high percentage or not is impossible to tell as we lack the adequate benchmarks.

On news sites, algorithmic personalisation is still less prevalent. People generally have the choice whether they want their online news to be personalised or not. Additionally, people who choose pre-selected personalisation are more likely to use an above-average amount of generalinterest news as well (Beam \& Kosicki, 2014), and to encounter messages that are not in line with their own ideas (Beam, 2013). However, as personalisation on news websites is still in its infancy, in the future the effects may be different (Thurman \& Schifferes, 2012; Turow, 2011).

While personalisation features on news sites themselves are not common yet, de facto algorithmic personalisation can arise on two other layers: news aggregators and social networks. Purely algorithmic news aggregators like Google News have mostly failed to become a major news source for a large audience, but more and more traffic to news sites goes via social media sites, which use a blend of algorithmic and human recommendations to define the supply of news items for the individual.

Social media sites can lead to two sources of personalisation. First, although people connect with different types of contacts (friends, family, colleagues etc.) on such sites, many people might mostly connect to people who resemble them. If someone's network is rather homogeneous, this means that the content shared by someone's contacts may be in line with the person's preferences as well. This argument is based on the assumption that people only share content they agree with - an assumption that has been challenged by some (Barbera, Jost, Nagler, Tucker, \& Bonneau, 2015; Morgan, Shafiq, \& Lampe, 2013).

Second, on some sites, most prominently on Facebook, an opaque algorithm determines what content is shown in a user's newsfeed. A recent study suggests that the influence of this algorithm is lower than the influence of the user's choices (Bakshy, Messing, \& Adamic, 2015). However, the validity of this study is debated among social science scholars and beyond (Lumb, 2015).

In sum, it looks as if either personalisation is still in its infancy on news sites, or we have too little empirical evidence on what is actually happening in this domain. More independent research is necessary.

\section{WHAT ARE THE EFFECTS OF PERSONALISATION?}

An even harder question concerns the long-term effects of personalisation. Does personalised 
content really influence people? Does, or could, personalisation really harm democracy? While the effects of self-selected personalisation on democracy have been studied in a number of experiments and surveys, the effects of pre-selected personalisation have not been investigated in a comprehensive academic study so far.

In general, we can expect effects of selective exposure or selective avoidance on two different variables that are relevant in democratic societies: political polarisation and political knowledge.

\section{POLARISATION AS A CONSEQUENCE OF SELF-SELECTED PERSONALISATION}

Numerous scholars of political communication have studied the effects of a selective media diet on democratic societies. Most of these studies are concerned with one potential consequence of selective exposure that might be harmful to democratic societies: partisan polarisation.

According to this line of research, people who are repeatedly exposed to biased information that favours a particular political standpoint that is close to their own will eventually develop more extreme positions and be less tolerant with regard to opposite points of view. Empirical evidence from the US supports this argument. For example, Stroud (2010) used representative American election survey data to show that Americans who adopt a homogenous partisan news diet become more extreme in their views during the campaign. Similar effects of self-selective exposure to partisan news on polarisation were also found in experimental settings (e.g. Knobloch-Westerwick \& Meng, 2011).

To understand the importance of cross-cutting information in a democracy, Price, Cappella, and Nir (2002) investigated the effects of being exposed to information in the mass media that contradicts existing attitudes and beliefs. They found that people who regularly encounter diverse opinions in the media are not only better able to provide reasons for their own political choices; they also have a better understanding of what motivates the perspective of others.

The effect of personalised news on polarisation is conditional on the political system. Most of the research on the effect of polarisation stems from the US, which is characterised by a bipolar political system, in which the issue of polarisation is substantially different than, for example, in the Dutch political system where more than ten parties compete with each other (e.g., Trilling, Van Klingeren, \& Tsfati, 2016). This difference between political systems must be kept in mind when discussing the effects of personalisation.

\section{POLITICAL LEARNING, AS IMPACTED BY SELF-SELECTED PERSONALISATION}

While there is a growing body of studies providing evidence that selective exposure is related to polarisation, evidence on the effect of selective exposure or selective avoidance on knowledge gains is scarce. Yet, there is a strong theoretical link between political knowledge and selfselected personalised communication.

First, many media users take advantage of the abundance of media outlets to avoid political information altogether. Hence, these users lose an important information source to form political opinions (Prior, 2007). Second, if media users select political information that is attractive to them, they will be better motivated to process the information they encounter.

Hence, personalisation might lead to knowledge gaps in society: News avoiders know little. Those who self-select political news learn more from the news. This holds in particular for online news sources where users can choose news they are interested in (Kenski \& Stroud, 
2006). However, the effects of self-selection of news on polarisation and political knowledge are - like most media effects - small. Additionally, the effect of a personalised and selective news menu is different for each individual, and many people are not affected (Valkenburg \& Peter, 2013). The fact that the relationships introduced above are statistically significant means that there is convincing empirical proof that selective exposure to news and polarisation and differential knowledge gains are related. Yet, the fact that the effect is small means that selective exposure to news explains only a small fraction of the variance in political attitudes and political knowledge we find in democratic societies.

One of the reasons for the small effect is that hardly anyone lives in an absolute information cocoon, as mentioned previously. In the current fragmented media landscape, people can access an abundance of news sources. In addition, we often get information about current events through conversations with colleagues, friends, or family members. In such conversations people may be introduced to news items, or to different perspectives. Cross-cutting conversations about politics also can occur online, mostly in an environment that does not usually deal with political information, like an online hobby group (Wojcieszak \& Mutz, 2009).

\section{EFFECTS OF PRE-SELECTED PERSONALISATION}

Empirical research into the long-term effects of pre-selected personalisation is scarce (see Van Hoboken, 2012). The lack of empirical evidence can be partly explained by the fact that algorithms which automatically pre-select news items for individual users have only been developed in the past few years.

It is, however, possible that potential effects of pre-selected personalisation are in line with effects of self-selected personalisation. Being repeatedly exposed to the same news frame, for example, may lead to reinforcing framing effects (Lecheler \& De Vreese, 2011). Potentially, algorithms that favour news items framing events in a perspective close to the reader's point of view will lead to a more polarised society. One of the first studies of news personalisation using search behaviour and social media as point of departure indeed found polarising effects, while also demonstrating an increase in cross-cutting exposure through social media (Flaxman, Goel, \& Rao, 2014)

With regard to systematic gaps of knowledge about current events, pre-selected personalisation might contribute to social sorting, as explained above. If algorithms are programmed to favour news items that cover only a small set of topics that users are assumed to be interested in, users will not be exposed to information on many other topics that are important for society at large. As interest in news and politics correlates with higher education and higher social economic status, this could lead to a divided citizenry.

Moreover, commercial news providers gain power because they can control the algorithm. For example, a recent experiment carried out by Facebook shows that they were able to influence people's emotions by manipulating content. The experiment involved manipulating the selection of user messages ('posts') that 689,003 users saw in their newsfeeds. "When positive expressions were reduced, people produced fewer positive posts and more negative posts; when negative expressions were reduced, the opposite pattern occurred" (Kramer, Guillory \& Hancock, 2014, p. 1). Hence, Facebook succeeded in influencing the emotions of users. However, the effects were rather small. In another study, the effects appeared to be stronger: Epstein and Robertson (2015) claim that differences in Google search results can shift voting preferences of undecided voters by $20 \%$.

As outlined in a previous section, news users have always limited their exposure to specific news 
items themselves: a process of self-selected personalisation. Perhaps pre-selected personalisation by algorithms merely anticipates choices that news users would have made themselves?

Even if it were true that personalisation could influence people deeply, would the many possibilities to broaden one's horizon outweigh the effects of personalisation? For example, the web offers many ways to encounter unexpected content.

The effects of personalisation may be counteracted by other forces. For example, people who self-select content on some blogs and encounter a lot of pre-selected content on their Facebook newsfeed may still be avid users of non-personalised news sites as well.

Another reason to doubt whether there is a big risk that personalised content will steer people's worldview is that current personalisation technologies may be insufficient. For instance, with targeted online advertising (behavioural targeting) the click-through rate on ads is around $0.1 \%$ to $0.5 \%$ (e.g. Chaffey, 2015). This suggests that algorithms of companies do not predict people's interests very accurately. After all, around 999 out of 1,00o people do not click on ads - perhaps the ads do not appeal to the interests of most people. On the other hand, the low click-through rate on ads could perhaps be explained by scepticism towards advertising rather than by bad personalisation.

In sum, there is no reason to worry about pre-selected personalisation leading to filter bubble problems, briefly put, because the technology is still insufficient. With technological developments, however, problems may arise. As Hildebrandt notes, pre-selected personalisation could be seen as an early example of ambient intelligence: technology that senses and anticipates people's behaviour in order to adapt the environment to their inferred needs (Hildebrandt, 2010). Consequently, algorithmic accountability through transparency becomes more and more important as the technology develops (Diakopoulos, 2014).

\section{CONCLUSION}

Some fear that personalised communication can lead to information cocoons or filter bubbles. In brief, the idea is that democratic society is at risk because personalised content and services limit the diversity of media content people are exposed to. In this way, personalisation could steer people's ideas and behaviour surreptitiously.

We discussed whether we should worry about filter bubbles. We distinguish between selfselected personalisation, where people actively choose which content they see, and pre-selected personalisation, where algorithms personalise content for users without any deliberate user choice. We summarised empirical research on the extent of personalisation in practice and on the effects of personalisation.

We conclude that - in spite of the serious concerns voiced - at present, there is no empirical evidence that warrants any strong worries about filter bubbles. Nevertheless, the debate about filter bubbles is important. Personalisation on news sites is still at an infant stage, and personalised content does not constitute a substantial information source for most citizens, as our review of literature on media use has shown. However, if personalisation technology improves, and personalised news content becomes people's main information source, problems for our democracy could indeed arise, as our review of empirical studies of media effects has shown. 
In the light of the rapidly changing media landscape, many studies become out-dated rapidly. In addition, existing studies mainly cover the US situation with its two-party political system, which means that the studies are only partly relevant for countries with multiparty systems.

One lesson we should have learned from the past is that panic does not lead to sane policies. More evidence is needed on the process and effects of personalisation, so we can shift the basis of policy discussions from fear to insight. 


\section{REFERENCES}

Bakshy, E., Messing, S., \& Adamic, L. (2015). Exposure to ideologically diverse news and opinion on Facebook. Science, 58(4), 707-731.

Barbera, P., Jost, J. T., Nagler, J., Tucker, J. A., \& Bonneau, R. (2015). Tweeting from left to right: Is online political communication more than an echo chamber? Psychological Science, Advance online publication.

Bax, E.H. (1988). Modernization and cleavage in Dutch society. A study of long term economic and social change. PhD Dissertation, Rijksuniversteit Groningen, Netherlands.

Beam, M. A. (2013). Automating the news: How personalized news recommender system design choices impact news reception. Communication Research, 14, 1019-1041

Beam, M. A., \& Kosicki, G. M. (2014). Personalized news portals: Filtering systems and increased news exposure. Journalism \& Mass Communication Quarterly, 91(1), 59-77.

Bimber, B., \& Davis, R. (2003). Campaigning online: The Internet in U.S. elections. New York: Oxford University Press.

Blekesaune, A., Elvestad, E., \& Aalberg, T. (2012). Tuning out the world of news and current affairs: An empirical study of Europe's disconnected citizens. European Sociological Review, 28(1), 110-126.

Blom, C.H., \& Talsma, J. (ed.) (2000). De verzuiling voorbij. Godsdienst, stand en natie in de lange negentiende eeuw. Amsterdam, Netherlands: Het Spinhuis.

Bond, R. M., Fariss, C. J., Jones, J. J., Kramer, A. D., Marlow, C., Settle, J. E., \& Fowler, J. H. (2012). A 61-million-person experiment in social influence and political mobilization. Nature, 489(7415), 295-298.

Bozdag, E. (2015), Bursting the Filter Bubble: Democracy, Design, and Ethics. Delft University of Technology, PhD thesis.

Chaffey Chaffey, D. (2015, April). Display advertising clickthrough rates. Smart Insights.

Retrieved from

http://www.smartinsights.com/internet-advertising/internet-advertising-analytics/display-adv ertising-clickthrough-rates/

Cohen, S. (1973). Folk devils and moral panics the creation of the Mods and Rockers. St Albans: Paladin.

Council of Europe, Recommendation CM/Rec(2012)3 of the Committee of Ministers to member States on the protection of human rights with regard to search engines, adopted by the Committee of Ministers on 4 April 2012.

Diakopoulos, N. (2014). Algorithmic accountability. Journalistic investigation of computational power structures. Digital Journalism, 3, 398-415.

http://doi.org/10.1080/21670811.2014.976411

Epstein, R., \& Robertson, R. E. (2015). The search engine manipulation effect (SEME) and its 
possible impact on the outcomes of elections. Proceedings of the National Academy of Sciences, 112(33), E4512-E4521.

European Commission (2013). 'Preparing for a Fully Converged Audiovisual World: Growth, Creation and Values (Green Paper) Brussels, COM(2013) 231 final' (24 March 2013)

$<$ https://ec.europa.eu/digital-agenda/sites/digital-

agenda/files/convergence_green_paper_en_o.pdf> accessed on 29 July 2015, p. 14 .

Festinger, L. (1957). A theory of cognitive dissonance. Stanford, CA: Stanford University Press.

Flaxman, S. R., Goel, S., \& Rao, J. M. (2014). Filter bubbles, echo chambers, and online news consumption. Retrieved from https://5harad.com/papers/bubbles.pdf

Gitlin, T. (1998). Public spheres or public sphericules. In T. Liebes \& J. Curran (Eds.), Media, ritual and identity (pp. 168-174). London: Routledge.

Garrett, R. K. (2009). Echo chambers online?: Politically motivated selective exposure among Internet news users. Journal of Computer-Mediated Communication, 14(2), 265-285.

Garrett, R. K. (2009). Politically motivated reinforcement seeking: Reframing the selective exposure debate. Journal of Communication, 59(4), 676-699.

Garrett, R. K., Carnahan, D., \& Lynch, E. K. (2011). A turn toward avoidance? Selective exposure to online political information, 2004-2008. Political Behavior, 35(1), 113-134.

Gutwirth, S. \& Hildebrandt, M. eds. (2008). Profiling the European Citizen. Dordrecht: Springer 2008.

Habermas, J (1989). The structural transformation of the public sphere: An inquiry into a category of bourgeois society. Cambridge, MA: MIT Press.

Hallin, D. C., \& Mancini, P. (2004). Comparing Media Systems. Cambridge, UK: Cambridge University Press.

Hannak, A., Sapiezynski, P., Molavi Kakhki, A., Krishnamurthy, B., Lazer, D., Mislove, A., \& Wilson, C. (2013). Measuring personalization of web search. In Proceedings of the $22 \mathrm{Nd}$ International Conference on World Wide Web (pp. 527-538). Geneva, Switzerland: International World Wide Web Conferences Steering Committee.

Helberger, N. (2011). Diversity by design. Journal of Information Policy, 1, 441-469.

Helberger, N., Kleinen-Von Königslöw, K. and Van der Noll, R. (2015). Regulating the new information intermediaries as gatekeepers of information diversity, info 17(6), p. 50-71.

Hildebrandt, M. (2010). Privacy en identiteit in slimme omgevingen. Computerrecht, 6, 172182.

Kenski, K., \& Stroud, N. J. (2006). Connections between Internet use and political efficacy, knowledge, and participation. Journal of Broadcasting \& Electronic Media, 5o(2), 173-192.

Kim, J., Kim, J., \& Seo, M. (2014). Toward a person $\times$ situation model of selective exposure: Repressors, sensitizers, and choice of online news on financial crisis. Journal Of Media Psychology: Theories, Methods, And Applications, 26(2), 59-69. 
Knobloch-Westerwick, S., \& Meng, J. (2011). Reinforcement of the Political Self Through Selective Exposure to Political Messages. Journal of Communication, 61(2), 349-368.

Kramer, A. D., Guillory, J. E., \& Hancock, J. T. (2014). Experimental evidence of massive-scale emotional contagion through social networks. Proceedings of the National Academy of Sciences, 111(24), 8788-8790.

Lazarsfeld, P. F., Berelson, B., \& Gaudet, H. (1944). The people's choice: How the voter makes up his mind in a presidential campaign. New York: Columbia University Press.

Lecheler, S., \& de Vreese, C. H. (2011). Getting real: The duration of framing effects. Journal of Communication, 61(5), 959-983.

Lijphart, A. (1968). Verzuiling, pacificatie en kentering in de Nederlandse politiek. Amsterdam: De Bussy.

Lumb, D. (2015). Why scientists are upset about the Facebook Filter Bubble story. Retrieved from:

http://www.fastcompany.com/3046111/fast-feed/why-scientists-are-upset-over-the-facebook-fi lter-bubble-study

Lyon, D. (2003). Surveillance as social sorting: Computer codes and mobile bodies. In D. Lyon (ed.) Surveillance as social sorting: Privacy, risk and automated discrimination (pp. 13-30). New York, NY: Routledge.

Morgan, J. S., Shafiq, M. Z., \& Lampe, C. (2013). Is news sharing on Twitter ideologically biased $\square$ ? In Proceedings of the 2013 conference on Computer supported cooperative work (pp. 887-897). ACM.

Negroponte, N. (1995). Being digital. New York, NY: Knopf.

O'Callaghan, D., Greene, D., Conway, M., Carthy, J., \& Cunningham, P. (2013). The extreme right filter bubble. arXiv preprint arXiv:1308.6149.

Pariser, E. (2011). The filter bubble: What the Internet is hiding from you. New York, NY: Penguin.

Pasquale F (2015). The black box society: The secret algorithms that control money and information. Cambridge: Harvard University Press.

Price, V., Cappella, J. N., \& Nir, L. (2002). Does disagreement contribute to more deliberative opinion? Political Communication, 19(1), 95-112.

Prior, M. (2007). Post-broadcast democracy: How media choice increases inequality in political involvement and polarizes elections. Cambridge, UK: Cambridge University Press.

Sears, D. O., \& Freedman, J. L. (1967). Selective exposure to information: A critical review. Public Opinion Quarterly, 31(2), 194-213.

Stroud, N. J. (2010). Polarization and partisan selective exposure. Journal of Communication, $60(3), 556-576$.

Stroud, N. J. (2011). Niche news: The politics of news choice. Oxford University Press. 
Sunstein, C. R. (2002). Republic.com. Princeton, NJ: Princeton University Press.

Sunstein C. R. (2006). Infotopia: How many minds produce knowledge. New York, NY: Oxford University Press

Dillahunt, T. R., Brooks, C. A., \& Gulati, S. (2015, April). Detecting and Visualizing Filter Bubbles in Google and Bing. In Proceedings of the 33rd Annual ACM Conference Extended Abstracts on Human Factors in Computing Systems (pp. 1851-1856). ACM.

Thurman, N., \& Schifferes, S. (2012). The future of personalization at news websites: Lessons from a longitudinal study. Journalism Studies, 13(5-6), 775-790.

Treiblmaier, H., Madlberger, M., Knotzer, N., \& Pollach, I. (2004, January). Evaluating personalization and customization from an ethical point of view: an empirical study. In System Sciences, 2004. Proceedings of the 37th Annual Hawaii International Conference on System Sciences (pp. 10-pp). IEEE.

Trilling, D., \& Schoenbach, K. (2013a). Patterns of news consumption in Austria: How fragmented are they? International Journal of Communication, 7, 929-953.

Trilling, D., \& Schoenbach, K. (2013b). Skipping current affairs: The non-users of online and offline news. European Journal of Communication, 28(1), 35-51.

Trilling, D., \& Schoenbach, K. (2015). Investigating people's news diets: How online news users use offline news. Communications: The European Journal of Communication Research, 4O(1), $67-91$.

Trilling, D., Van Klingeren, M., \& Tsfati, Y. (2016). Selective exposure, political polarization, and possible mediators: Evidence from the Netherlands. International Journal of Public Opinion Research, online first. doi:10.1093/ijpor/edwoo3

Turow, J. (2011). The daily you: How the new advertising industry is defining your identity and your worth. New Haven, CT: Yale University Press.

Van Hoboken, J. V. J. (2012). Search engine freedom: on the implications of the right to freedom of expression for the legal governance of search engines. Alphen aan den Rijn, Netherlands: Kluwer Law International.

Valkenburg, P. \& Peter, J.(2013). The differential susceptibility to media effects model. Journal of Communication 63(2), 221-243.

Vilse-Freiberga, V., Däubler-Gmelin, H., Hammersley, B., Pessoa Maduro, L.M.P. (2013). A free and pluralistic media to sustain European democracy. Retrieved from http://ec.europa.eu/digital-agenda/sites/digital-agenda/files/HLG\%2oFinal\%2oReport.pdf

Wojcieszak, M. E., \& Mutz, D. C. (2009). Online groups and political discourse: Do online discussion spaces facilitate exposure to political disagreement? Journal of Communication, $59(1), 40-56$.

Wijfjes, H. (ed.) (2004). Journalistiek in Nederland. Beroep, cultuur en organisatie 1850-200o. Amsterdam, Netherlands: Boom.

Zaller, J. R. (1992). The nature and origins of mass opinion. Cambridge, UK: Cambridge 
University Press.

Zarsky, T. Z. (2002). Mine your own business: making the case for the implications of the data mining of personal information in the forum of public opinion. Yale Journal of Law and Technology 5, 1-56.

Zuiderveen Borgesius, F.J. (2015). Improving privacy protection in the area of behavioural targeting, Alphen aan den Rijn, Netherlands: Kluwer Law International. 